\title{
VIBRATIONS RESONANCE ESTIMATION IN MARINE STRUCTURES
}

\author{
Lech Murawski \\ Gdynia Maritime University \\ Faculty of Marine Engineering \\ Morska Street 81-87, 81-225 Gdynia, Poland \\ tel.: +48586901 480, fax: +48586901399 \\ e-mail:lemur@wm.am.gdynia.pl
}

\begin{abstract}
Dynamic analyses of marine structures are one of the most important during design process as well as during exploitation. Typically, two parts of vibrations calculations are performed. Firstly, natural vibrations frequencies and modes are determined. Forced vibrations analysis is the second step of calculations. Natural vibrations give us information about possibility (e.g. at which main engine speed) of dangerous vibrations amplitudes (resonances threat). Exact values of vibrations amplitudes are results of forced vibrations analysis. Confidence level (error value) of forced vibration calculations is much lower in comparison to uncertainty of natural vibration analysis. What is more, form engineering practice point of view, natural vibrations frequencies estimation (resonance avoidance) is the most important during dynamic analysis of marine structures with propulsion systems. In the paper some examples of dynamic characteristics estimation and their changing methods (possibility) was presented. Utility of relatively simple models, with low degree of freedom number, was discussed. Modelling methods depending on the analysis target of marine slow-speed crankshafts was presented. Advantages and disadvantages of subcritical and supercritical design of marine propulsion system were discussed. An example of propulsion system natural torsional vibrations simplified analysis was presented. Location of the main torsional resonance is one of the most important decisions during design process of the marine propulsion system. Methods of fast and easy estimation as well as changing possibility of natural vibrations frequencies of marine structures is the main objective of presented paper.
\end{abstract}

Keywords: vibration, dynamic analysis, marine structures, propulsion system, crankshaft, resonance

\section{Introduction}

Safety of sea navigation requires that marine structures have to be free from excessive vibrations. While designing the systems, we must take into account the potential effects of engine and component malfunction and variability in characteristic values such as stiffness and damping of flexible couplings and dampers or engine misfire conditions. Where torques, stresses or amplitudes are found to exceed the limits for continuous operation, restrictions in speed and/or power will be imposed.

Two-stroke, slow speed main engines have been installed mostly on merchant ships. The engines are connected to a directly driven propeller by a relatively short shaft line. The propulsion system described above has a lot of advantages (mainly efficiency) but is the source of a relatively high vibration level. What is more, rough sea can be a source of added ship vibration, especially for big container carrier [2, 5,9]. Vibrations may have a dangerous influence on crew comfort, ship equipment strength and consequently on the ship safety. Therefore, many authors examine the vibration characteristics and vibration control of complex ship hull structures [6]. But still, the propulsion system is a main source of ship vibration and methodology of power transmission system analysis is very important from designers' point of view.

The ability to predict a propulsion system operating parameters and excitations of the other ship structures, by numerical analysis is very important. During the design process, all changes are possible and cheap, but when the ship is built, they become nearly impossible. Incorrect design of the power transmission system may be the cause of propulsion failure or excessive excitation 
forces leading to a high level of vibration of the other marine structures. Reliability of the power transmission system in use is closely correlated with safety of navigation at sea.

All classification societies require calculations of the propulsion system operating parameters but they have no simplified formulas. There are several numerical algorithms (mostly based on the Finite Element Method - FEM) for shaft line alignment and vibration analysis. The FEM model of a typical marine propulsion system is shown in Fig. 1. But these numerical algorithms are unobtainable and not easy to use for ship crew as well as other unspecialized engineers. They are too complicated, time-consuming, and expensive. In author opinion, the chief of marine engineers should have possibility to estimate vibrations level of some marine structures. Estimation method of some engineering vibrations problems are the main thesis of this paper.

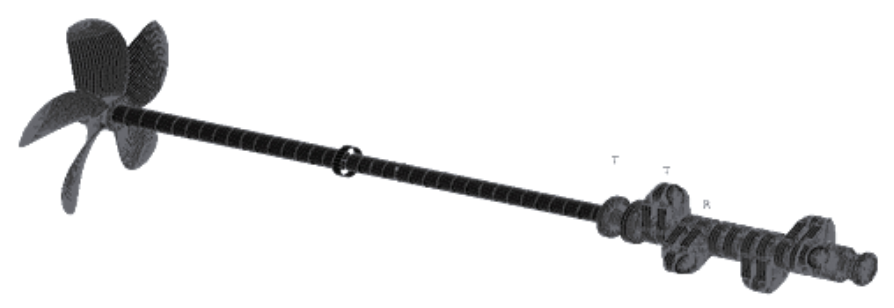

Fig. 1. FEM model of a typical marine propulsion system

\section{Natural vibration frequencies estimation}

General dependence of vibrations is presented in equation (1). Dampings have an insignificant influence on natural vibration frequency and mode. Natural vibrations are defined as motion without excitations. What is more, just for estimation, only one degree of freedom model of engineering structure can be analysed in several cases. Engine or other marine machines (like pumps) mounted on elastic foundation can be modelled by very simple model shown in Fig. 2. In that case, equation (1) may be simplified to equation (2).

$$
\boldsymbol{M} \ddot{x}+\boldsymbol{C} \dot{x}+\boldsymbol{K} x=M_{E}(t),
$$

where:

$\boldsymbol{M}$ - mass matrix,

$\boldsymbol{C} \quad$ - damping matrix,

$\boldsymbol{K}-$ stiffness matrix,

$M_{E}(t)$ - excitation vector,

$\mathrm{x} \quad$ - displacement.

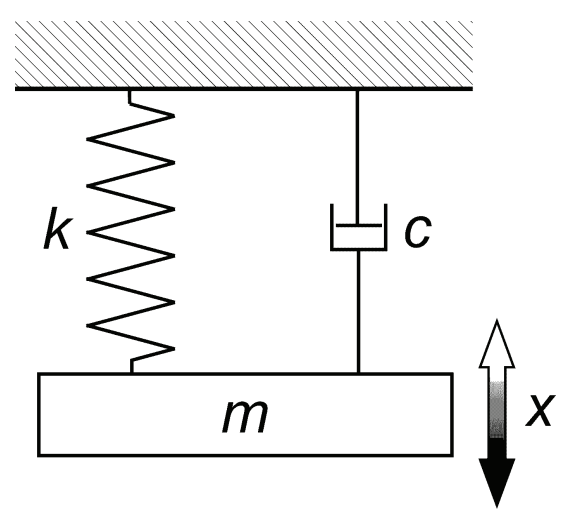

Fig. 2. Simplified model for vibration estimation of marine machines 


$$
\mathbf{m} \ddot{\mathbf{x}}+\mathbf{k x}=\mathbf{0} .
$$

On the base of solution of equation (2), the natural frequency can be estimated by dependence (3) and/or (4).

$$
\begin{aligned}
& \omega_{N}=\sqrt{\frac{k}{m}}[\mathrm{rad} / \mathrm{s}], \\
& \mathbf{f}_{N}=\frac{1}{2 \pi} \cdot \sqrt{\frac{\mathbf{k}}{\mathrm{m}}}[\mathrm{Hz}],
\end{aligned}
$$

Determination of the torsional resonance location is the most important problem. Natural frequency should be denoted as accurately as possible. Especially the supercritical (above main natural frequency) design of propulsion system can provide the barred speed range (around main resonance area). As it was said above, the total value of damping in the system has an insignificant influence on stress level outside the resonance level. The damping effect has to be taken into account in the range of approximate width of $\pm 15 \%$ around the main resonance (see Fig. 3 ). The typical damping coefficient (DC) of marine structure vibrations is between 3-6\%.

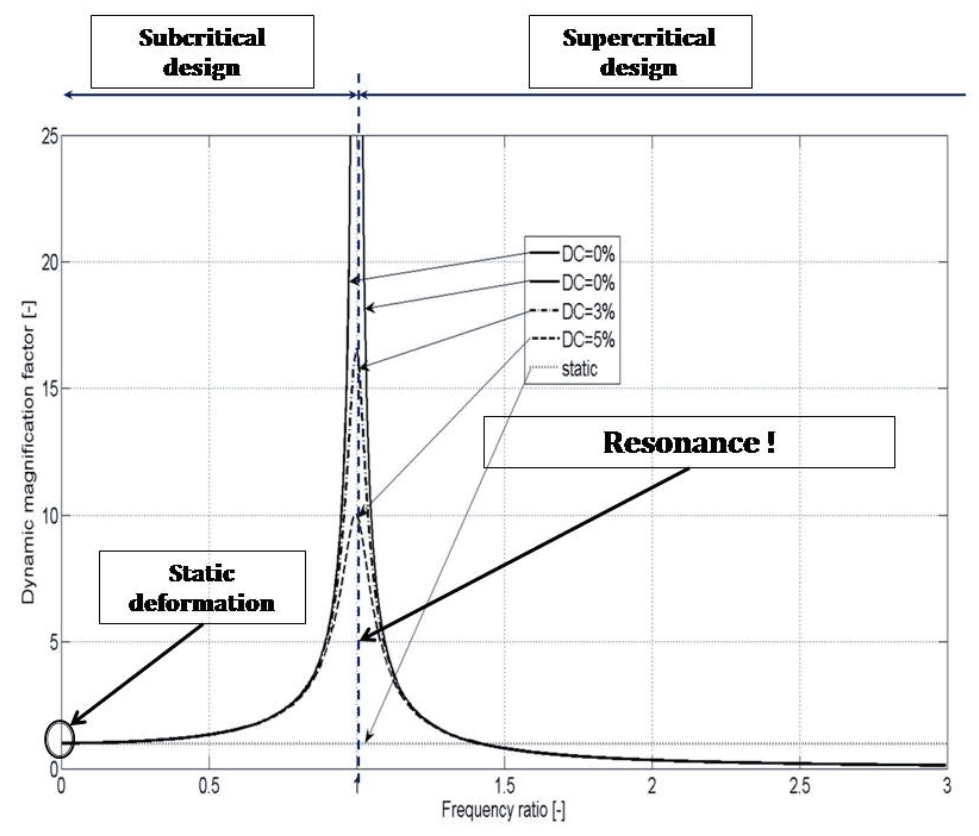

Fig. 3. Simplified model for vibration estimation of marine machines

Based on equation (4) and Fig. 3, an engineer can perform estimation of structure dynamic behaviour. Usually the mass of the analysed device (e.g. pump) is known. Total stiffness of foundation pads can be easily estimated e.g. on the base of equation (5). Therefore, estimation of main natural frequency value is easy with use of dependence (4).

$$
\mathbf{k}=\mathbf{E} \frac{\mathbf{s}}{\mathbf{h}_{\mathbf{0}}}
$$

where:

$E$ - Young's modulus,

$S$ - area of total cross section of foundation pads,

$h_{0}-$ height of the pads.

Main excitation frequency can be calculated on the base of engine revolutions and number of working cylinders as it was shown in equation (6). Of course, if working cycle is performed once per two revolutions (four-stroke engine) our excitation value has to be divided by 2 . 


$$
f_{E}=\frac{n}{60} \cdot i,
$$

where:

$n$ - machine revolutions [rpm],

$i$ - cylinder's number.

Sketch of given machine can be drown. An example of marine structure dynamic analysis is presented in Fig. 4. Resonance curve of analysed machine was drown as a solid line indicated by " $\mathrm{k}$ " letter (resonance curve for machine mounted on the foundation pads with $\mathrm{k}$ stiffness). In our case, the natural frequency is equal to $6 \mathrm{~Hz}$. If our excitation frequency (vertical line named "Excit. 1") is equal to $6.4 \mathrm{~Hz}$ (only 7\% detuning) the excessive value of vibration amplitude may be observed (about $12 \mathrm{~mm} / \mathrm{s}$ in our example - intersection between " $k$ " line and "Excit. I" line). The engineer has two possibility of changing excessive vibration: increase or decrease of foundation stiffness. If the stiffness is increased two times the natural frequency is equal to $8.5 \mathrm{~Hz}$ (axial line in Fig. 4). If the stiffness is decreased two times the natural frequency is equal to $4.2 \mathrm{~Hz}$ (dotted line in Fig. 4). Both solutions (stiffness increasing and decreasing) give us similar results: the amplitude goes to $2.5-3 \mathrm{~mm} / \mathrm{s}$ (intersection between axial or dotted line and "Excit. I" line). If our excitation is strongly supercritical ("Excit. 2" $-7.5 \mathrm{~Hz}$ ) the vibration speed amplitude is equal to $3.5 \mathrm{~mm} / \mathrm{s}$. In that case stiffness increasing will be a source of higher vibration level $-4.5 \mathrm{~mm} / \mathrm{s}$. Greater elasticity (dotted line) gives us better vibration level - below $2 \mathrm{~mm} / \mathrm{s}$. Opposite situation can be observed for subcritical excitation ("Excit. 3" $-4.8 \mathrm{~Hz}$ ). If the foundation stiffness is two times increasing then vibration speed amplitudes is decreased from $5.5 \mathrm{~mm} / \mathrm{s}$ to $1.5 \mathrm{~mm} / \mathrm{s}$. Stiffness decreasing is a source of much higher vibration level $-14 \mathrm{~mm} / \mathrm{s}$.

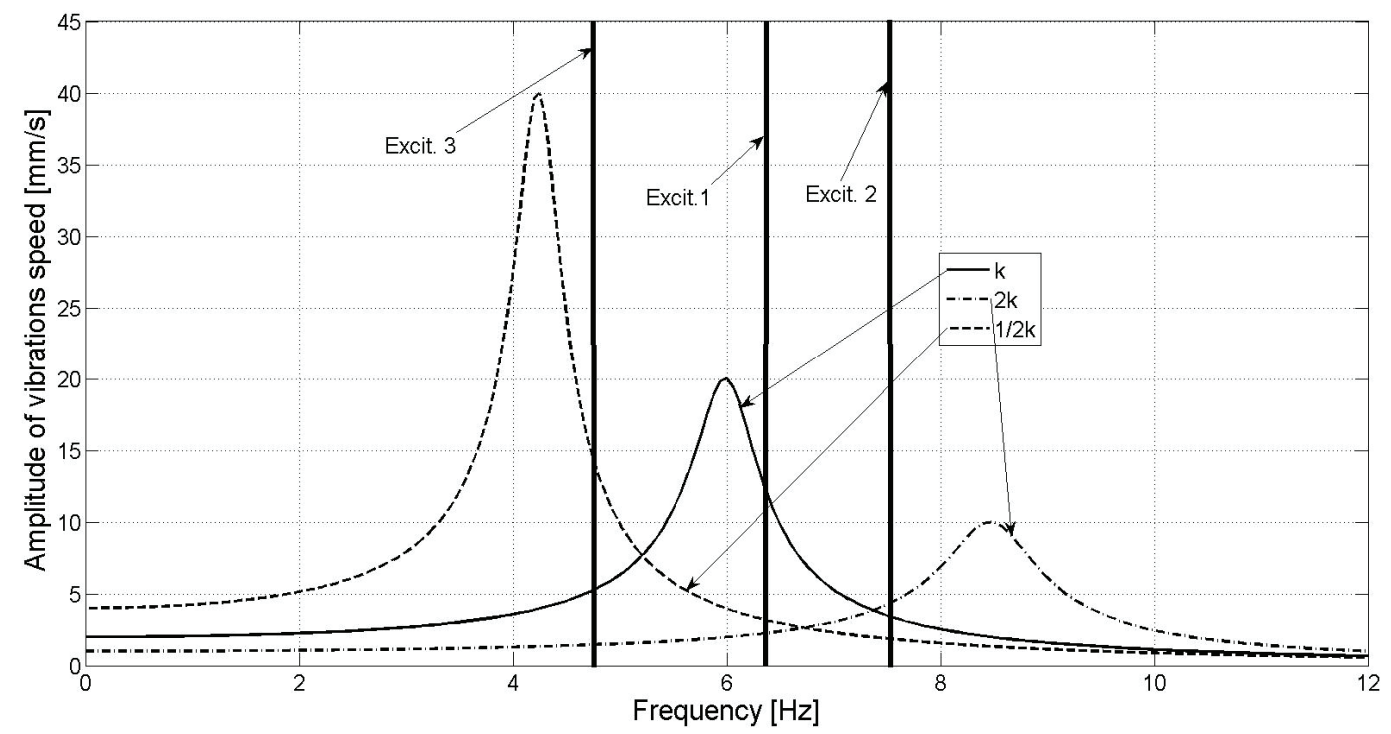

Fig. 4. Example of resonance curves of analysed machine

Engineer should always remember of resonance curve because sometimes structure stiffening gives the desired result and a sometimes better result gives the bigger elasticity. Vibration level estimation is possible based on knowledge of simple equations and resonance curve.

\section{Example of modelling methods of propulsion system torsional vibration}

Torsional vibrations of the marine power transmission system are usually the most dangerous for the shaft line and the crankshaft [3]. Torsional vibrations are the result of the pulsing torque of the reciprocating combustion engine [4] as well as reciprocating propeller's power output. All system components like the crankshaft, intermediate shaft, propeller shaft and optional couplings 
and gears have to transmit the static and additionally dynamic torque. Research methods of torsional vibrations have been developed since the 1950s [7, 10]. All classification societies require calculations of the propulsion system operating parameters but they have no simplified formulas [11-13]. There are several numerical algorithms (mostly based on the Finite Element Method) for shaft line alignment and vibration analysis. But those numerical algorithms are unobtainable and not useful for ship crew and designers. They are too complicated, timeconsuming, and expensive.

The design formulas based on static torque analysis do not take into consideration the possibility of dangerous torsional vibration stresses, and where the propulsion critical speed (resonance) is located. Dangerous torsional vibration stresses may occur within the operating range. Calculations should be performed up to $120 \%$ of the rated speed. The classification societies define the stress limits for propeller shafts, an intermediate shafts, and crankshafts [11-13]. In general, the stress limit for the crankshaft is a constant and for the shaft, line is defined as a rotating speed function. When torsional vibration stresses exceed the limits, at revolutions within the operating range, a barred speed range should be provided. Continuous operating of the main engine is prohibited in the barred range; the main engine revolutions have to be changed as quickly as possible. In the barred speed range, a higher vibratory stress level is allowable. Barred ranges are not acceptable in a speed range between 0.8 and 1.05 of the rated speed. The width of the barred speed range should be defined; it should be equal to about $\pm 10 \%$ with respect to the critical engine speed.

The torsional vibration conditions may, for certain installations, require a torsional vibration damper. From the author's experience, it may be said that this need may arise for the following types of propulsion system: plants with controllable propeller pitch, plants with 8-cylinder engines and plants with unusual shafting layout and for special owner requirements. Four-, five- and sixcylinder engines require special attention. Because of the heavy excitation, the natural frequency of a system with one-node vibration should be situated away from the normal operating speed range, to avoid effecting it. This can be achieved by changing the masses and/or the stiffness of the system so as to give a much higher, or much lower natural frequency, called undercritical or overcritical running, respectively.

In the undercritical case, one-node resonance vibration with the main critical order should occur about $35-45 \%$ above the nominal engine speed. Such undercritical conditions can be realised by choosing a rigid shaft system, leading to a relatively high natural frequency. The characteristics of an undercritical propulsion system are normally: a relatively short shafting system, probably no tuning wheel, a turning wheel with relatively low inertia and large diameters of shafting. The large shaft diameters allow the use of material with a moderate ultimate tensile strength, but requiring careful shaft alignment (due to the relatively high bending stiffness). The main advantage of undercritical propulsion is that the system does not have a barred speed range. The highest torsional stress level in the nominal main engine speed is a disadvantage. When running undercritical, significant varying torque at nominal conditions of about $100-150 \%$ of the mean torque is expected. This torque induces a significant varying propeller thrust.

In the overcritical case, one-node natural vibration frequency is adjusted in a way that resonance with the main critical order occurs about 30-70\% below the nominal engine speed. Such overcritical conditions can be realised by choosing an elastic shaft system, leading to a relatively low natural frequency. The characteristics of an undercritical propulsion system are normally a tuning wheel necessary on the crankshaft fore end, a turning wheel with relatively high moment of inertia and shafts with relatively small diameters, requiring shafting material with a relatively high ultimate tensile strength. A barred speed range is expected in this propulsion system. Torsional vibrations in overcritical conditions may, in special cases, have to be eliminated by the use of a torsional vibration damper. 
Usually, only torsional vibrations with one and two nodes need to be considered. The main critical order, causing the largest extra stresses in the shaft line and crankshaft, is normally the vibration with an order equal to the number of cylinders i.e., six cycles per revolution on a sixcylinder engine. This resonance is positioned at the engine speed corresponding to the natural torsional frequency divided by the number of cylinders.

The author proposed estimation method of natural torsional vibrations of power transmission system. The main assumption stating that two nodes model (two degrees of freedom) is sufficient for the first estimation of the torsional vibration frequency and mode. The assumption is based on practical experience $[3,8]$. First mode of torsional vibrations is dominant for two-stroke, low speed marine diesel engines. Simplified model of the power transmission system designed to estimate the torsional vibration is presented in Fig. 5. Polar moment of inertia of propeller with propeller shaft is marked as $\boldsymbol{I} \boldsymbol{p}$. Polar moment of inertia of crankshaft with intermediate shaft $\left(\boldsymbol{I}_{\boldsymbol{k}}\right)$ (with flywheels and reciprocating masses), was calculated as a simple sum of components (e.g. cranks). If we try to take into consideration the crankshaft stiffness, we have to calculate the equivalent polar moment of inertia of crankshaft part of propulsion system $\left(\boldsymbol{I}_{\boldsymbol{k} s}\right)$. Torsion stiffnesses of the shaft line are marked by $\boldsymbol{k}_{1}$ and $\boldsymbol{k}_{2}$.

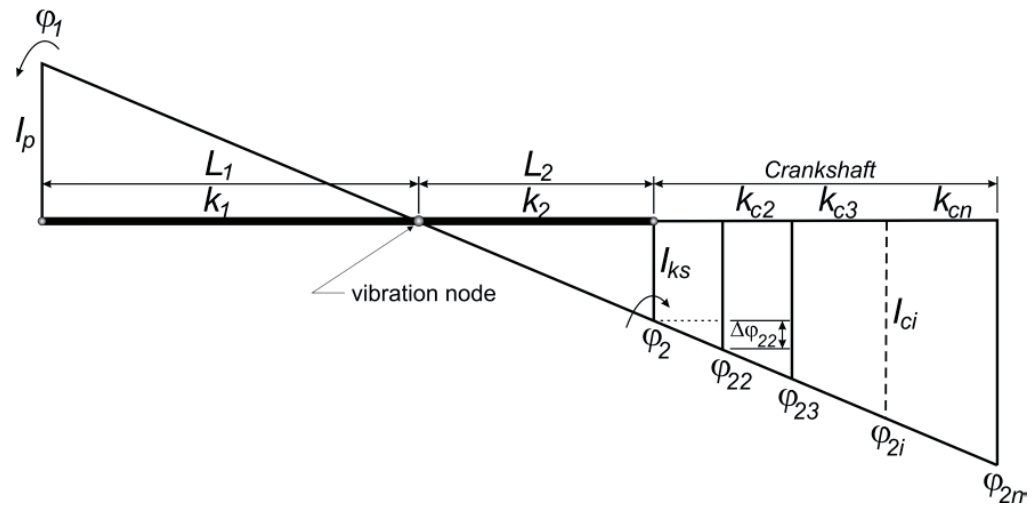

Fig. 5. Model of the power transmission system with crankshaft stiffness taken into account

The substitute mass moment of inertia of crankshaft can be determined on the base of equation (7). It should be stressed that the substitute mass moment of inertia is much greater than the simple sum of cranks moments of inertia. Therefore, natural torsional frequency is smaller in the propulsion system model when considering crankshaft stiffness.

$$
I_{k s}=I_{c 1}+I_{c 2}\left(1+\frac{k_{2}}{k_{c 1}}\right)+I_{c 3}\left(1+\frac{k_{2}}{k_{c 1}}+\frac{k_{2}}{k_{c 2}}\right)+\cdots+I_{c n}\left(1+\sum_{i=2}^{n} \frac{k_{2}}{k_{c_{i}-1}}\right),
$$

where:

$I_{k s}$ - substitute mass moment of inertia of crankshaft part of propulsion system,

$I_{c i}$ - mass moment of inertia of $\mathrm{i}^{\text {th }}$ crank of crankshaft,

$k_{2}$ - torsional stiffness between vibration node and crankshaft,

$k_{c i}$ - torsional stiffness of $\mathrm{i}^{\text {th }}$ crank of crankshaft.

The next assumption is that generally the location of torsional vibration node does not change. Therefore, $\boldsymbol{k}_{2}$ stiffness can be estimated based on equation (8).

$$
\mathbf{k}_{2}=\mathbf{k}_{\mathbf{s}} \frac{\mathbf{I}_{\mathbf{p}}+\mathbf{I}_{\mathbf{k}}}{\mathbf{I}_{\mathbf{p}}}
$$

where:

$k_{s}$ - global torsional stiffness of the shaftline,

$I_{p}$ - mass moment of inertia of propeller with propeller shaft,

$I_{k}$ - mass moment of inertia of crankshaft with intermediate shaft. 
Determination of substitute mass moment of inertia $\left(\boldsymbol{I}_{\boldsymbol{k}}\right)$ allows us to use the author's method of torsional vibration frequency determination. Torsional natural frequency can be denoted on the basis of equation (9) $\left(\boldsymbol{I}_{\boldsymbol{k}}=\boldsymbol{I}_{\boldsymbol{k} \boldsymbol{s}}\right)$ considering crankshaft stiffness.

$$
f_{N}=\frac{d_{e}^{2}}{8} \cdot \sqrt{\frac{1}{2 \pi} \cdot \frac{G}{L_{s}} \cdot \frac{I_{p}+I_{k}}{I_{p} \cdot I_{k}}}[H z],
$$

where:

$f_{N}$ - torsional natural frequency in Hertz,

$d_{e}$ - shaft diameter,

$G$ - shear modulus,

$L_{s}$ - shaftline length.

Presented methodology was verified on the example of 2600 TEU container ship power transmission system. Propulsion system of the ship is equipped with a slow-speed, two-stroke, seven-cylinder main engine: MAN B\&W 7 S70 MC-C type. The engine main parameters are as follows: power $-21735 \mathrm{~kW}$, nominal speed $-91 \mathrm{rpm}$, flywheel (turning wheel) $-14455 \mathrm{kgm}^{2}$. The propulsion system is equipped with five-blade propeller having $7.42 \mathrm{~m}$ in diameter, the mass in air $-33700 \mathrm{~kg}$ and moment of inertia $-107200 \mathrm{kgm}^{2}$. The diameter of the intermediate shaft is equal to $595 \mathrm{~mm}$ and the diameter of the propeller shaft equals $675 \mathrm{~mm}$. The propulsion system was designed as overcritical (barred speed range is expected).

Torsional vibrations of the propulsion system presented above were calculated by an independent design office and measured by another specialized team. Numerical analysis was prepared using specialized program based on Finite Element Method (FEM). The measurements were performed by another independent firm with the application of strain gauges. Calculating and measuring results were compared with the results obtained on the basis of the authors' equations. The results comparison of torsional natural frequency of the analysed power transmission system is as follows:

- calculations by independent design office:

$$
f_{N c}=4.858 \mathrm{~Hz}
$$

- measurements:

$$
f_{N m}=5.03 \mathrm{~Hz}
$$

- estimation on the base of equation (9):

$$
f_{N}=4.798 \mathrm{~Hz} \text {. }
$$

The verification shows that errors level between the proposed methodology and "reality“ is acceptable. The highest differences are around resonance revolutions and were caused by damping coefficients assumptions. In the authors' opinion, the presented estimation method might be useful for marine engineers and designers.

\section{Conclusions}

Vibration level estimation is possible based on knowledge of simple equations and resonance curve. Engineer should always remember of resonance curve because sometimes structure stiffening gives the desired result and a sometimes better result gives the bigger elasticity.

The calculations method presented in chapter 3 have been compared with the analogical calculations made by independent numerical programs [1] in an independent design office as well as compared with the measuring data obtained by other independent specialized team. The results conformity is good - the differences between natural frequency values were less than $5 \%$. In the author's opinion, the estimation method presented above might prove useful for marine engineers and designers. 


\section{References}

[1] Aarvik, J. A., Software for shafting systems, DNV Software News, No. 3, pp. 11, 2005.

[2] Andersen, I.M.V, Jensen J. J., Measurements in a container ship of wave-induced hull girder stresses in excess of design values, Marine Structures, Vol. 37, pp. 54-85, 2014.

[3] Brydum, L., Jakobsen, S. B., Vibration characteristics of two-stroke, low speed diesel engines, MAN B\&W Diesel a/s, pp. 1-16, Copenhagen 1987.

[4] Geveci, M., Osburn, A.W., Franchek, M. A., An investigation of crankshaft oscillations for cylinder health diagnostics, Mechanical Systems and Signal Processing, Vol. 19, pp. 1107-1134, 2005.

[5] Iijima, K, Yao, T., Moan, T., Structural response of a ship in severe seas considering global hydroelastic vibrations, Marine Structures, Vol. 21, pp. 420-445, 2008.

[6] Lin, T. R, Pan, J, O'Shea, P. J, Mechefske, C. K., A study of vibration and vibration control of ship structures, Marine Structures, Vol. 22, pp. 730-743, 2009.

[7] Nestorides, E. J., A Handbook on Torsional Vibration, Cambridge University Press, 1958.

[8] Murawski, L., Static and Dynamic Analyses of Marine Propulsion Systems, Oficyna Wydawnicza Politechniki Warszawskiej, p. 148, Warszawa 2003.

[9] Senjanović, I., Vladimir, N., Tomić, M., Hadžić, N., Malenica, Š., Some aspects of structural modelling and restoring stiffness in hydroelastic analysis of large container ships, Ships and Offshore Structures, Vol. 9, No. 2, pp. 199-217, 2014.

[10] Wilson, W. K., Practical Solution of Torsional Vibration Problems, Chapman \& Hall LTD, London 1963.

[11] Bureau Veritas, Rules for steel ships, Part C: Machinery, Electricity, Automation and Fire Protection, Chapter 1: Machinery, Section 9: Shaft Vibrations, Article 3: Torsional vibrations, January 2014.

[12] Det Norske Veritas, Rules for classification of ships, Rotating Machinery, Power Transmission, Chap. 4, P. 4, July 2013.

[13] Germanisher Lloyd, Rules \& Guidelines, Naval Ship Technology, Propulsion Plants, Chapter 2, III-1-2, 2012. 